\title{
Infectious pleural effusion status and treatment progress
}

\author{
Wei Yang ${ }^{1}$, Bo Zhang ${ }^{1}$, Ze-Ming Zhang ${ }^{2}$ \\ ${ }^{1}$ Department of Respiratory Medicine, Medical School of Chinese PLA, Beijing 100853, China; ${ }^{2}$ Department of Respiratory Medicine, Pudong New \\ Area Zhoupu Hospital, Shanghai 201318, China \\ Contributions: (I) Conception and design: W Yang, B Zhang; (II) Administrative support: W Yang, B Zhang; (III) Provision of study materials or \\ patients: B Zhang, ZM Zhang; (IV) Collection and assembly of data: B Zhang, ZM Zhang; (V) Data analysis and interpretation: W Yang, ZM Zhang; \\ (VI) Manuscript writing: All authors; (VII) Final approval of manuscript: All authors. \\ Correspondence to: Bo Zhang. Department of Respiratory Medicine, Medical School of Chinese PLA, No. 28 of Fuxing Road, Haidian District, \\ Beijing 100853, China. Email: zhangbo_gg88@163.com.
}

\begin{abstract}
Pleural cavity infection continuously seriously threatens human health with continuous medical progress. From the perspective of pathophysiology, it can be divided into three stages: exudative stage, fibrin exudation and pus formation stage, and organization stage. Due to the pathogenic bacteria difference of pleural cavity infection and pulmonary infection, it is very important for disease treatment to analyze the bacteria and biochemical characteristics of the infectious pleural effusion. Most prognoses of patients have been relatively good, while for some patients, the complicated parapneumonic effusion or empyema could be evolved. Antibiotic treatment and sufficient drainage are the foundation for this treatment. No evidence can support the routine use of a fibrin agent. However, it has been reported that the plasminogen activator and deoxyribonuclease can be recommended to be applied in the pleural cavity. In case of failure on conservative medical treatment, operative treatment can be applied such as thoracoscopy and pleural decortication. According to the clinical characteristics of these patients, it is a key to research prognosis, as well as early evaluation and stratification, in the future.
\end{abstract}

Keywords: Infectious pleural effusion; empyema; status quo; treatment progress

Submitted Apr 26, 2017. Accepted for publication Oct 13, 2017.

doi: $10.21037 /$ jtd.2017.10.96

View this article at: http://dx.doi.org/10.21037/jtd.2017.10.96

\section{Introduction}

In 2,500 years ago, Hippocrates in ancient Greek found pleural cavity infections; and these have continuously seriously influenced human health at present, even though constant progress has been made in the field of microbiology, antibiotics, operation and other fields. Approximately 80,000 British and American adults have suffered from thoracic cavity infection each year, with medical expenses of approximately USD 500 million $(1,2)$. Even though the prognosis of most patients has been relatively good, serious complications could occur for some patients. Furthermore, the fatality rate has reached up to $20 \%$ (3). For elderly people with underlying diseases, the fatality rate has reached up to $30 \%(4,5)$. The above situation can be related to the poor basic conditions of patients, improper selection of antibiotics or antimicrobial resistance, and other factors $(6,7)$. In addition, there is a question of how much do we understand this disease completely. In order to answer this, we need to answer the following questions: (I) How does pleural cavity infection occur? (II) How can we early detect and diagnose pleural cavity infection? (III) How do we select antibiotics at the primary treatment stage? (IV) If antibiotic treatment becomes invalid, what would be our basis for selecting other treatment methods such as chest drainage (8), intrapleural cavity injection (9), medical thoracoscopy (10) and surgical operation (11), and how do we evaluate the prognosis of these patients (12)? 


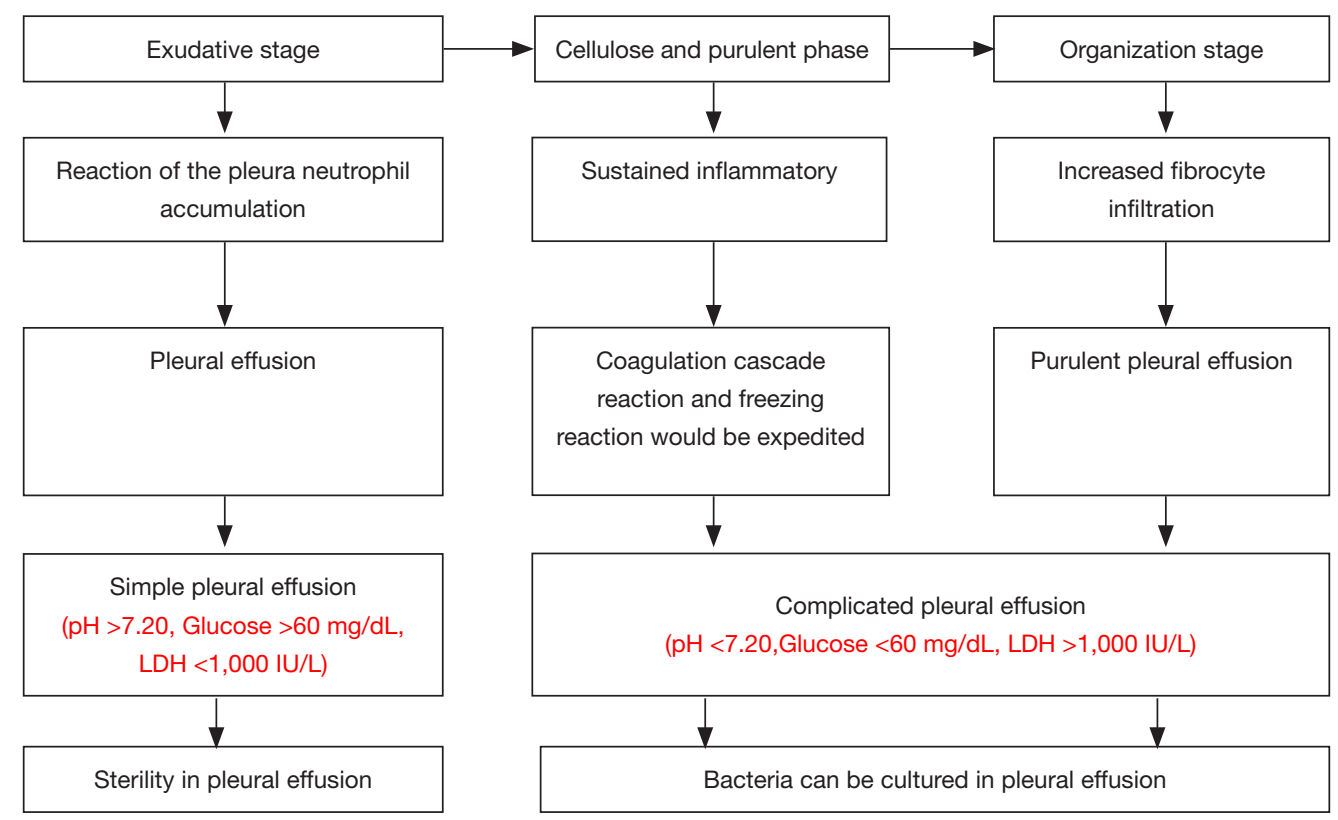

Figure 1 Pathophysiology process.

\section{Epidemiology}

Globally (13-15), pleural cavity infection occurrence rate has been constantly increasing for each age group with an unknown cause $(1,16)$. For example, from 1996 to 2008, admission rate has been increased two times for the patients suffering from empyema in America (3.04-5.98/100,000) (1). These changes are possibly related to the enhancement of clinical diagnosis awareness and the increasing number of available examination methods, allowing physicians to better identify pleural cavity infection. Furthermore, this may also be related to the increasing age of the elderly year by year.

Pleural cavity infection is often secondary to pulmonary infection. Pleural effusion occurs in $15-44 \%$ of admitted patients suffering from pneumonia, in which $40 \%$ of patients are complicated with parapneumonic effusion or abscess $(17,18)$. For pneumonia treatment, exceeding non-steroidal anti-inflammatory drugs are applied at the early stage, which could easily cause pleural effusion $(16,19,20)$. The empyema in $50 \%$ of patients was deprived from pneumonic pleural effusion. The occurrence rate of thoracic cavity infection for males was two times than that for females. Furthermore, the incidence rate of diabetes, long-term excessive drinking, drug taking and rheumatoid arthritis for these patients were higher than that for the normal population $(1,5)$. In addition, $2 / 3$ of patients with chronic lung disease or immunodeficiency disease are complicated with parapneumonic effusion or empyema; and anaerobic pleural cavity infection occurred in patients with poor oral hygiene and those who accidentally inhaled the infection (21). Other patients were secondary to operative wound and iatrogenic injury $(1,4,5,16)$, while $1 / 3$ patients failed to be influenced by high-risk factors. Moreover, the fatality rate of hospital-acquired pleural infection was higher than that of community-acquired pleural infection $(4,22,23)$.

\section{Pathophysiology process}

Pleural cavity infection can be divided into three stage (Figure 1). The first stage is the exudative stage. Due to the inflammatory reaction of the pleura and neutrophil accumulation, the blood vessel endothelium can be damaged and permeability would be increased; at the same time, the fluid would enter the pleural cavity, forming the pleural effusion $(17,24,25)$. At such stage, glucose level would be normal during the pleural effusion and no biochemical evidence can be detected for the microorganism and microorganism invasion (26). The second stage is the fibrin exudation and pus formation stage. Multiple proinflammatory factors would stimulate neutrophils for migration and fibrocytes for chemotaxis (25). Furthermore, the endothelial permeability of blood vessels would be 
further improved. The bacteria enter the pleural cavity, and bacteria and bacterial degradation products can be detected in the effusion. Due to the phagocytosis of the bacterial metabolism and neutrophils, lactic acid would increase, pleural effusion $\mathrm{pH}$ and glucose would decrease and lactic dehydrogenase would be elevated. At the same time, the coagulation cascade reaction and freezing reaction would be expedited. Furthermore, fibrin would be deposited in the visceral pleura and parietal pleura, fibrin decomposition would be reduced, and pleural adhesion and encapsulated pleural effusion would occur. The third stage is the organization stage. Due to increased fibrocyte infiltration, one layer of the fibreboard will form on the surface of visceral pleura and parietal pleura, and an inelastic and compact fiber membrane will form between two layers of the pleura. The thickened fibrous tissue would encapsulate the lung, preventing the lung from expansion. Improper treatment can easily cause chronic pleural cavity infection.

According to different $\mathrm{pH}$, glucose and lactate dehydrogenase (LDH) levels in the pleural effusion, these can be divided as follows: uncomplicated parapneumonic effusion, complicated parapneumonic effusion, and empyema. A simple pleural cavity infection can be related to the exudative stage. Hence, antibiotic treatment can be applied. In addition, complicated pleural cavity infection and empyema requires drainage or operative treatment (27). Thus, different clinical stages need different clinical decisions (28).

\section{Diagnosis}

A typical infectious pleural effusion may possibly cause findings similar to pneumonia, and the diagnosis can be easy. However, attention should be given to potential pleural effusion or empyema in patients with pneumonia $(29,30)$. Chest ultrasonic examination is very sensitive to pleural effusion (31). If the ultrasonic examination shows that the membrane increased in the pleural effusion with multiple signs of complicated parapneumonic effusion, the high echo in the thoracic cavity may be possibly related to pus in the pleural cavity. The chest X-ray examination shall select the posteroanterior position + lateral position as far as possible, rather than a simple posteroanterior position or anteroposterior position for X-ray examination (32). The chest CT scan is not highly sensitive to the membrane in the pleural cavity, but it can distinguish patients with the complicated parapneumonic effusion and peripheral pulmonary abscess, and investigate patients with a combination of lung malignant tumors and pleural effusion through the marks on the pleura. Furthermore, it can also distinguish among lung parenchyma, the developing agent and pleural effusion through enhanced CT scan.

The pathogenic bacteria can be confirmed for some patients only $(23,33)$. Therefore, pleural effusion analysis would be a very convenient method to understand this disease. For example, the $\mathrm{pH}$ value of the infectious pleural effusion and malignant pleural effusion, tuberculous pleuritis and rheumatoid arthritis can be reduced, while the $\mathrm{pH}$ value of the pleural effusion caused by proteusbacillus vulgaris can be increased. Furthermore, the $\mathrm{pH}$ value of the encapsulated pleural effusion on different positions can be also different. Hence, these special conditions shall be considered for $\mathrm{pH}$ value analysis. At the same time, other changes in these indicators shall be additionally analyzed, such as LDH and glucose. If confirming the diagnosis through pleural effusion analysis fails, this can also be referred to pleural biopsy or medical thoracoscopy, for patients with tuberculous pleuritis or malignant tumors, in particular (Figure 2).

\section{Treatment}

Infectious pleural effusion treatment concentrates on antibiotics, chest drainage, intrapleural cavity injection, thoracoscopy, surgical operation and other aspects (34).

\section{Antibiotic treatment}

Antibiotic treatment is the main treatment means, especially for children (7). Primary treatment needs to be combined with bacteriology knowledge $(5,21)$, the geographic location of the patient, the infection occurrence place (community or hospital), and the host status for drug selection. At the early stage, antibiotics application would be beneficial to physical rehabilitation and empyema occurrence prevention (19). Subsequent treatment shall refer to the bacteria source and culture results (blood, phlegm and pleural effusion), as well as antibiotics activity in the pleural effusion for adjustment of antibiotics (35). The thoracic cavity and lungs are significantly different in terms of oxygen content, $\mathrm{pH}$ and others; thus, the bacterial spectrum of the thoracic cavity infection would be not be completely same as that of the pneumonia $(4,36)$. The most common pathogen of community-acquired pleural infection is streptococcus $(37,38)$, followed by anaerobion and staphylococcus (such subject is pathogen, so the added coverage is unsuitable, I 


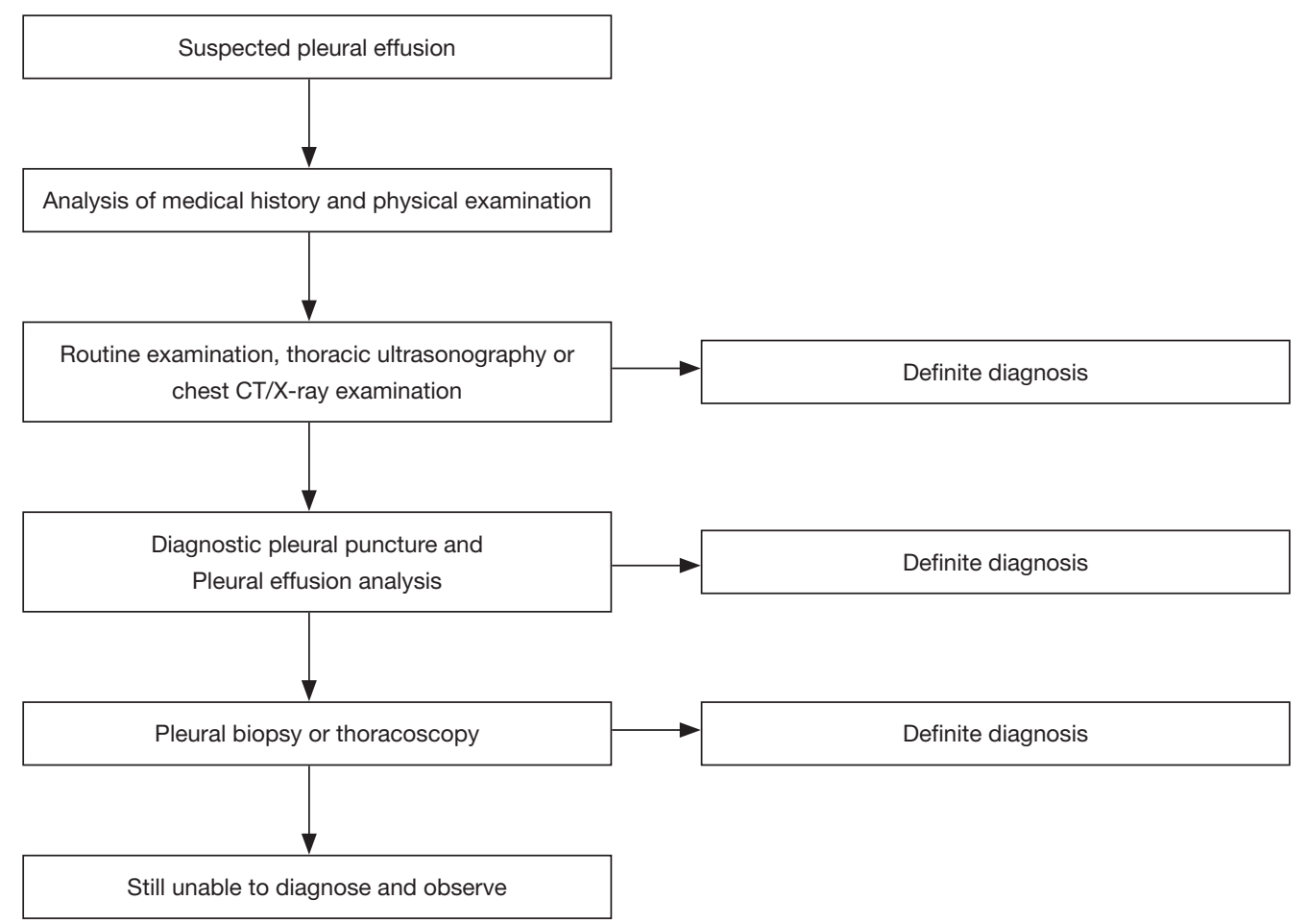

Figure 2 The infectious pleural effusion diagnosis process.

think). The proportion of the staphylococcus in hospitalacquired pleural infection and gram-negative bacteria is higher, and the proportion of methicillin-resistant staphylococcus aureus (MRSA) can reach up to $25 \%$; while the proportion of streptococcus in hospital-acquired infection is very low.

We shall select drugs (such as $\beta$ lactam, clindamycin and metronidazole) that penetrate into the pleural cavity as far as possible, in order to avoid the application of aminoglycoside drugs (poor penetration and inactivation in the acid environment). At the same time, we cannot recommend the use of antibiotics in the thoracic cavity (23). For community-acquired pleural infection, the combination of penicillin + Blactamase inhibitor would be selected (28). For the patients with penicillin anaphylaxis, clindamycin + fluoroquinolone, or third-generation cephalosporin and carbapenem would be applied. MRSA and drug-resistance gram-negative bacteria are the most common bacteria in hospital-acquired pleural infection. Thus, at the primary treatment stage, the above two kinds of bacteria needs to be covered (vancomycin, linezolid, carbapenem, thirdgeneration cephalosporin and others), as well as anaerobion (metronidazole or clindamycin) $(28,39)$.
In recent years, the incidence rate of fungal infection of the pleura has continuously increased year by year (40). Candida mycoderma bacteria and aspergillus are the most common pathogenic bacteria. Furthermore, legionella pneumonia and mycoplasma pneumonia rarely cause pleural infection. The disease course is self-limited, and empyema is rarely caused. Thus, macrolide antibiotics are not commonly applied for the pleural infection. If the pathogenic bacteria is confirmed through culture, the drug shall be adjusted according to culture results; but pathogenic bacteria fails to be cultured for over $40 \%$ of these patients. Therefore, culture method improvements or nucleic acid amplification technology applications need to be further discussed, in order to improve the positive rate of microbiological diagnosis (23).

Antibiotic treatment needs 3-4 weeks in general (23). If treatment time is less than two weeks, recurrence would be possible. Children-acquired pleural infection belongs to community-acquired infection. Streptococcus pneumoniae is the most common pathogen $(38,41-43)$, and the fatality rate is not more than $1 \%(1,42)$. However, staphylococcus aureus infection rate has been exhibiting an increasing trend recently (44). 


\section{Thoracocentesis and chest drainage tube placement}

Drainage is a key treatment of infectious pleural effusion (28). Thoracocentesis and chest drainage tube placement are applied in general. Effusion quantity $\geq 1 / 2$, pleural effusion $\mathrm{pH} \leq 7.15$, glucose $\leq 40 \mathrm{mg} / \mathrm{dL}$, $\mathrm{LDH}>2,000 \mathrm{U} / \mathrm{L}$, purulent effusion and positive culture are the independent predictive factors of chest drainage (45). Most physicians tend to catheterized drainage. However, a study in Germany considered that chest drainage fails to shorten admission time relative to thoracocentesis (46). Traditional opinions think that a large-diameter drainage tube ( $>24 \mathrm{~F}$ ) is beneficial to pleural effusion drainage, while a small-diameter drainage tube (10-14 F) can also receive a similar effect $(30,46,47)$, and can be easily accepted by these patients. Ultrasound-guided drainage tube placement technology is very practical for patients with serious diseases, empyema, encapsulated effusion and pleural thickening (8). To date, there have been no related highquality clinical studies on the most applicable drainage tube for chest drainage.

\section{Intrapleural cavity injection}

Traditional opinions have considered that increased fibrin in infectious pleural effusion and multiple septation formation would not be beneficial to effusion drainage. Hence, the fibrinolytic agent can be applied for improvement of drainage. A series studies also considered that the streptokinase or urokinase used in the pleural cavity can reduce hospital stay, prognosis improvement $(9,47-51)$ and prevent catastrophic hazards $(4,50,52,53)$. However, the largest random and controlled clinical study considers that streptokinase application in the pleural cavity has failed to improve hospital stay, death rate and others, to date (22) and a researcher also considers that the fibrinolytic agent has failed to reduce fatality rate (54). At present, the application of a fibrinolytic agent has been in dispute in complicated parapneumonic effusion (55). Since the fibrinolytic agent plays a role based on fibrinoclase activation, the fibrinoclase level in the pleural effusion is very low, thereby limiting its role. In the guideline, the routine application of a fibrinolytic agent has not been recommended (30). However, this guideline only suggests that the fibrinolytic agent can be applied at the early stage when empyema or pleural effusion is encapsulated, and the dosage has not reached an agreement $(30,34)$.

Tissue-type plasminogen activator (tPA) can be combined with fibrin to activate plasminogen combined with fibrin, and this can play a role of septation destruction in the pleural cavity, pleural effusion viscosity change and bacterial biofilm destruction that is not influenced by the plasminogen in the pleural effusion. This reduces operative risk (56) and hospital stay (4), and improves prognosis (57). Deoxyribonuclease (Dnase) can reduce purulent chest fluid viscosity (58). In the study on the combination of tPA + Dnase in the pleural cavity, pleural effusion drainage volume, operative referral rate, hospital stay and death rate in the treatment group significantly improved, compared to those in the control group $(4,59)$; in a safe and effective manner (60).

\section{Medical thoracoscopy treatment}

Medical thoracoscopy can bring less wound and adverse effects, and hold an important position in pleural effusion diagnosis with an unknown cause. At the same time, it can also be very practical when malignant pleural effusion or tuberculous pleuritis is particularly suspected (61). Medical thoracoscopy can separate the membrane and adhesive band, remove infected tissues, absorb the adhesive band, wash the thoracic cavity, and place the chest drainage tube under direct vision, allowing it to be beneficial to disease treatment. Studies have found that medical thoracoscopy treatment has been effective for complicated parapneumonic effusion treatment for approximately $90 \%$ of patients $(6,62)$. However, there are no random, controlled and large sample clinical studies at present, and its safety data has been insufficient. Thoracoscopy treatment is suggested when conservative medical treatment fails (28).

\section{Operation}

Pleural infection treatment is based on antibiotics + chest drainage (or drug injection) (38). However, for some patients, such treatment may fail, and operative treatment would be applied such as clearance of focal lesion and pleural decortication. Most lung functions of patients would be improved after the operation, blood perfusion would increase (63), and the success rate would exceed 85\% (64). However, the prognosis of patients who received terminal disease operation would be relatively poor. Thus, operation opportunity selection would be a key. In Multicenter Intrapleural Sepsis Trial 1 (MIST1) and Multicenter Intrapleural Sepsis Trial 2 (MIST2) studies, operative rate was $18 \%$ and $11 \%$, respectively $(4,22)$. Though the 


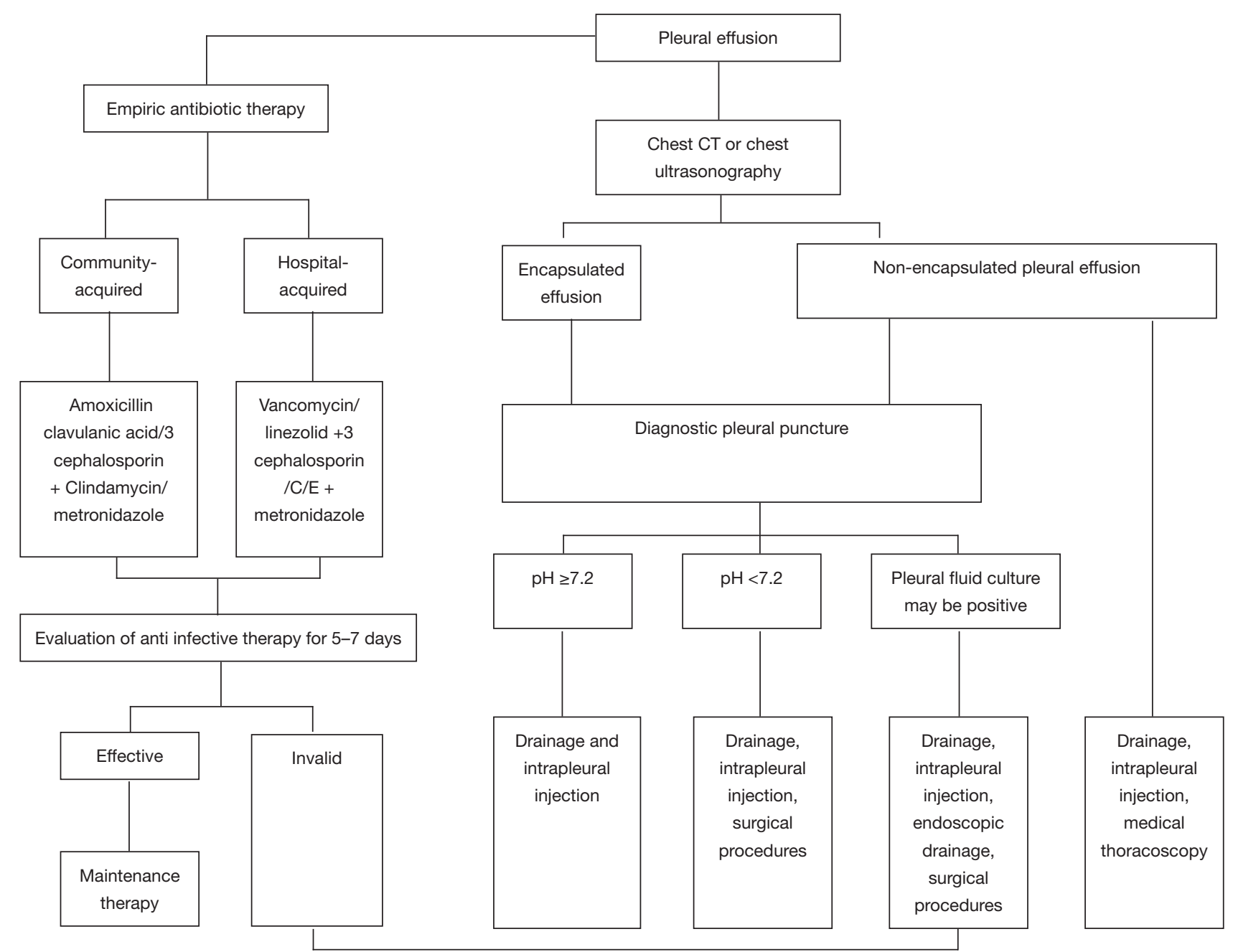

Figure 3 The infectious pleural effusion treatment process

empyema is not operation indication at the early stage (22), early operation intervention can improve prognosis and shorten hospital stay $(16,64)$. However, there are some operative risks, such as: perioperative mortality is $6 \%$, postoperative complications can reach up to $20 \%$ (2), and the half of these patients continues to suffer from chronic pain after one year $(39,40)$.

Video-assisted thoracic surgery (VATS) can obtain an effect similar to transthoracic surgery (65). In addition, such surgery has less damage, and is applicable for older patients, those with the fragile health, and those with complicated underlying diseases in particular (11). Transthoracic pleural decortication has been increasingly replaced by VATS (66). Compared with isolated chest drainage, VATS can significantly improve the prognosis of patients and shorten hospital stay (67). In Korea, a study suggested that VATS can be a first-line treatment of pleural cavity infection (64). Some studies also consider that death rate does not have a significant difference between thoracoscopic surgery and conservative medical treatment $(2,68)$, and have some contradictory results for the study and comparison between children VATS and medical treatment $(2,65,66,69)$. Furthermore, there is a lack of high-quality, random and controlled clinical studies on VATS/medical treatment. There are similar studies, but several design defects continue to exist (23).

The operation decisions for these patients are subjective due to failure on explicit indicators for operation opportunity confirmation. It is suggested to consider operative treatment when patients continue to develop sepsis 
with pleural effusion after antibiotic treatment and chest drainage. If conservative treatment exceeds 3-7 days (28) and antibiotics, pleural fluid drainage + intrapleural injection and other treatments fail to receive good effects, or there is evidence that the empyema is forming, operative treatment can be considered $(27,30,34)$. However, largescale and high-quality prospective studies have confirmed the objective indicators and optimal node for operative treatment.

\section{Supportive treatment}

Patients with pleural infection have a systemic inflammatory response status, with high metabolic rate and malnutrition; but its nutritional factor can be ignored by these people. Once hypoproteinemia develops, the prognosis of patients would be poor in general $(27,34)$. Hence, nutrition support needs to be strengthened (70). Though performing operative treatment, the prognosis of patients would be poor with short stature and poor nutrition (71). Therefore, once patients are found to be malnourished, nutritional support treatment shall be timely given; and water, electrolyte and acid-base balance shall be kept at the same time (Figure 3).

\section{Summary and outlook}

The incidence rate of pleural cavity infection continuously increased year by year, causing severe social harm. Advanced age, multiple complications, malignant tumor, immunosuppressor applications and others are high-risk factors of treatment failure. The prognosis of patients with confirmed pathogenic bacteria is significantly better than patients with unconfirmed pathogenic bacteria (72). Antibiotic treatment, chest drainage, intrapleural cavity injection, thoracoscopy, operation and nutrition support can be selective methods. Taking these patients as the center, summarize patient information and conduct comprehensive analysis to provide support for clinical decisions (68) and finding patients with potentially poor prognosis at the early stage in the future. At present, there have been studies on independent predictive factors, such as white blood cell count, pleural pain, pleural effusion position and pleural rupture for operative treatment (12). In addition, studies have been conducted by scholars on laboratory examination, radiological characteristics, complication characteristics and others aspects of the characteristics of different types of pleural effusion for ordinary community-acquired pneumonia and combined community-acquired pneumonia (73), in order to evaluate the prognosis of patients and actively conduct treatment. The above studies are beneficial attempts.

\section{Acknowledgements}

We are particularly grateful to all the people who have given us help on our article.

\section{Footnote}

Conflicts of Interest: The authors have no conflicts of interest to declare.

\section{References}

1. Grijalva CG, Zhu Y, Nuorti JP, et al. Emergence of parapneumonic empyema in the USA. Thorax 2011;66:663-8.

2. Sonnappa S, Cohen G, Owens CM, et al. Comparison of urokinase and video-assisted thoracoscopic surgery for treatment of childhood empyema. Am J Respir Crit Care Med 2006;174:221-7.

3. Finley C, Clifton J, Fitzgerald JM, et al. Empyema: an increasing concern in Canada. Can Respir J 2008,15:85-9.

4. Rahman NM, Maskell NA, West A, et al. Intrapleural use of tissue plasminogen activator and DNase in pleural infection. N Engl J Med 2011;365:518-26.

5. Nielsen J, Meyer CN, Rosenlund S. Outcome and clinical characteristics in pleural empyema: a retrospective study. Scand J Infect Dis 2011;43:430-5.

6. Corcoran JP, Hallifax R, Rahman NM. New therapeutic approaches to pleural infection. Curr Opin Infect Dis 2013;26:196-202.

7. Dorman RM, Vali K, Rothstein DH. Trends in treatment of infectious parapneumonic effusions in U.S. children's hospitals, 2004-2014. J Pediatr Surg 2016;51:885-90.

8. Abusedera M, Alkady O. Ultrasound-guided Pleural Effusion Drainage With a Small Catheter Using the Single-step Trocar or Modified Seldinger Technique. J Bronchology Interv Pulmonol 2016;23:138-45.

9. Porcel JM, Valencia H, Bielsa S. Manual Intrapleural Saline Flushing Plus Urokinase: A Potentially Useful Therapy for Complicated Parapneumonic Effusions and Empyemas. Lung 2017;195:135-8.

10. Shin JA, Chang YS, Kim TH, et al. Surgical decortication as the firstline treatment for pleural empyema. J Thorac 
Cardiovasc Surg 2013;145:933-9.

11. Hsiao CH, Chen KC, Chen JS. Modified single-port nonintubated video-assisted thoracoscopic decortication in high-riskparapneumonic empyema patients. Surg Endosc 2017;31:1719-27.

12. Chang CC, Chen TP, Yeh CH, et al. A simple weighted scoring system to guide surgical decision-making in patients with parapneumonic pleural effusion. J Thorac Dis 2016;8:3168-74.

13. Li ST, Tancredi DJ. Empyema hospitalizations increased in US children despite pneumococcal conjugate vaccine. Pediatrics 2010;125:26-33.

14. Goldbart AD, Leibovitz E, Porat N, et al. Complicated community acquired pneumonia in children prior to the introduction of the pneumococcal conjugate vaccine. Scand J Infect Dis 2009;41:182-7.

15. Wu PS, Huang LM, Chang IS, et al. The epidemiology of hospitalized children with pneumococcal/lobar pneumonia and empyema from 1997 to 2004 in Taiwan. Eur J Pediatr 2010;169:861-6.

16. Farjah F, Symons RG, Krishnadasan B, et al. Management of pleural space infections: a population-based analysis. J Thorac Cardiovasc Surg 2007;133:346-51.

17. Dean NC, Griffith PP, Sorensen JS, et al. Pleural Effusions at First ED Encounter Predict Worse Clinical Outcomes in Patients With Pneumonia. Chest. 2016;149:1509-15.

18. Chalmers JD, Singanayagam A, Murray MP, et al. Riskfactors for complicated parapneumonic effusion and empyema on presen-tation to hospital with communityacquired pneumonia. Thorax 2009;64:592-7.

19. Kotsiou OS, Zarogiannis SG, Gourgoulianis KI. Prehospital NSAIDs use prolong hospitalization in patients with pleuro-pulmonary infection. Respir Med 2017;123:28-33.

20. Krenke K, Krawiec M, Kraj G, et al. Risk factors for local complications in children with community acquired pneumonia. Clin Respir J 2016. [Epub ahead of print].

21. Meyer CN, Rosenlund S, Nielsen J, et al. Bacteriological aetiology and antimicrobial treatment of pleural empyema. Scand J Infect Dis 2011;43:165-9.

22. Maskell NA, Davies CW, Nunn AJ, et al. First Multicenter Intrapleural Sepsis Trial (MIST1) Group. U.K. Controlled trial of intrapleural streptokinase for pleural infection. $\mathrm{N}$ Engl J Med 2005;352:865-74.

23. Maskell NA, Batt S, Hedley EL, et al. The bacteriology of pleural infection by genetic and standard methods and its mortality significance. Am J Respir Crit Care Med 2006;174:817-23.
24. Porcel JM. Pleural fluid tests to identify complicated parapneumonic effusions. Curr Opin Pulm Med 2010;16:357-61.

25. Idell S. The pathogenesis of pleural space loculation and fibrosis. Curr Opin Pulm Med 2008;14:310-5.

26. Psallidas I, Corcoran JP, Rahman NM. Management of Parapneumonic Effusions and Empyema. Semin Respir Crit Care Med. 2014;35:715-22.

27. Bhatnagar R, Maskell NA. Treatment of complicated pleural effusions in 2013. Clin Chest Med 2013;34:47-62.

28. Davies HE, Davies RJ, Davies CW. BTS Pleural Disease Guideline Group.Management of pleural infection in adults: British Thoracic Society Pleural Disease Guideline 2010. Thorax 2010;65:ii41-ii53.

29. Lim WS, Baudouin SV, George RC, et al. BTS guidelines for the management of community acquired pneumonia in adults: update 2009. Thorax 2009;64 Suppl 3:iii1-55.

30. Maskell N; British Thoracic Society Pleural Disease Guideline Group. British Thoracic Society Pleural Disease Guidelines--2010 update. Thorax 2010;65:667-9.

31. Sperandeo M, Rotondo A, Guglielmi G, et al. Transthoracic ultrasound in the assessment of pleural and pulmonary diseases: use and limitations. Radiol Med 2014;119:729-40.

32. Moffett BK, Panchabhai TS, Nakamatsu R, et al. Comparing posteroanterior with lateral and anteroposterior chest radiography in the initial detection of parapneumonic effusions. Am J Emerg Med 2016;34:2402-7.

33. Anie Y, Sumi S, Varghese P, et al. Diagnostic approaches in patients with tuberculous pleural effusion. Diagn Microbiol Infect Dis 2007;59:389-94.

34. Villena Garrido V, Cases Viedma E, Fernández Villar A, et al. Recommendations of Diagnosis and Treatment of Pleural Effusion. Update. Arch Bronconeumol. 2014;50:235-49.

35. Teixeira LR, Sasse SA, Villarino MA, et al. Antibiotic levels in empyemic pleural fluid. Chest 2000;117:1734-9.

36. Burgos J, Lujan M, Falcó V, et al. The spectrum of pneumococcal empyema in adults in the early 21 st century. Clin Infect Dis 2011;53:254-61.

37. Birkenkamp K, O'Horo JC, Kashyap R, et al. Empyema management: A cohort study evaluating antimicrobial therapy. J Infect 2016;72:537-43.

38. Krenke K, Urbankowska E, Urbankowski T, et al. Clinical characteristics of 323 children with parapneumonic pleural effusion and pleuralempyema due to community acquired pneumonia. J Infect Chemother 2016;22:292-7.

39. Maclayton DO, Hall RG II. Pharmacologic treatment 
options for nosocomial pneumonia involving methicillinresistant Staphylococcus aureus. Ann Pharmacother 2007;41:235-44.

40. Wahidi MM, Willner DA, Snyder LD, et al. Diagnosis and outcome of early pleural space infection following lung transplantation. Chest 2009; 135:484-91.

41. Krenke K, Sadowy E, Podsiadły E, et al. Etiology of parapneumonic effusion and pleural empyema in children. The role of conventional and molecular microbiological tests. Respir Med 2016;116:28-33.

42. Li ST, Tancredi DJ. Empyema hospitalizations increased in US children despite pneumococcal conjugate vaccine. Pediatrics 2010;125:26-33.

43. Langley JM, Kellner JD, Solomon N, et al. Empyema associated with community-acquired pneumonia: a Pediatric Investigator's Collaborative Network on Infections in Canada (PICNIC) study. BMC Infect Dis 2008;8:129.

44. Mahon C, Walker W, Drage A, et al. Incidence, aetiology and outcome of pleural empyema and parapneumonic effusion from 1998 to 2012 in a population of New Zealand children. J Paediatr Child Health 2016,52:662-8.

45. Porcel JM, Valencia H, Bielsa S. Factors influencing pleural drainage in parapneumonic effusions. Rev Clin Esp 2016;216:361-6.

46. Rahman NM, Maskell NA, Davies CW, et al. The relationship between chest tube size and clinical outcome in pleural infection. Chest 2010;137:536-43.

47. Singh M, Mathew JL, Chandra S, et al. Randomized controlled trial of intrapleural streptokinase in empyema thoracis in children. Acta Paediatr 2004;93:1443-5.

48. Diacon AH, Theron J, SchuurmansMM, et al. Intrapleural streptokinase for empyema and complicated parapneumonic effusions. Am J Respir Crit Care Med 2004; 170:49-53.

49. Bilgin M, Akcali Y, Oguzkaya F. Benefits of early aggressive management of empyema thoracis. ANZ J Surg 2006;76:120-2.

50. Misthos P, Sepsas E, Konstantinou M, et al. Early use of intrapleural fibrinolytics in the management of postpneumonic empyema. A prospective study. Eur J Cardiothorac Surg 2005;28:599-603.

51. Cha LM, Choi S, Kim T, et al. Intrapleural urokinase therapy in a neonate with pleural empyema. Pediatr Int 2016;58:616-9.

52. Janda $S$, Swiston J. Intra-pleural fibrinolytic therapy for treatment of adult parapneumonic effusions and empyemas: a systematic review and meta-analysis. Chest
2012;142:401-11.

53. Diacon AH, Koegelenberg CF, Bolliger CT. A trial of intrapleural streptokinase. N Engl J Med 2005;352:2243-5.

54. Cameron R, Davies HR. Intra-pleural fibrinolytic therapy versus conservative management in the treatment of adult parapneumonic effusions and empyema. Cochrane Database Syst Rev 2008;16:CD002312.

55. Corcoran JP, Rahman NM. Point: should fibrinolytics be routinely administered intrapleurally for management of a complicated parapneumonic effusion? Yes. Chest 2014;145:14-7.

56. Thommi G, Shehan JC, Robison KL, et al. A double blind randomized cross over trial comparing rate of decortication and efficacy of intrapleural instillation of alteplase vs placebo in patients with empyemas and complicated parapneumonic effusions. Respir Med 2012;106:716-23.

57. James CA, Braswell LE, Pezeshkmehr AH, et al. Stratifying fibrinolytic dosing in pediatric parapneumonic effusion based on ultrasound grade correlation. Pediatr Radiol 2017;47:89-95.

58. Simpson G, Roomes D, Heron M. Effects of streptokinase and deoxyribonuclease on viscosity of human surgical and empyema pus. Chest 2000;117:1728-33.

59. Mehta HJ, Biswas A, Penley AM, et al. Management of Intrapleural Sepsis with Once Daily Use of Tissue Plasminogen Activator and Deoxyribonuclease. Respiration 2016;91:101-6.

60. Bishwakarma R, Shah S, Frank L, et al. Mixing It Up: Coadministration of tPA/DNase in Complicated Parapneumonic Pleural Effusions and Empyema. J Bronchology Interv Pulmonol 2017;24:40-7.

61. Rahman NM, Ali NJ, Brown G, et al. Local anaesthetic thoracoscopy: British Thoracic Society Pleural Disease Guideline 2010. Thorax 2010;65:ii54-ii60.

62. Brutsche MH, Tassi GF, Györik S, et al. Treatment of sonographically stratified multiloculated thoracic empyema by medical thoracoscopy. Chest 2005;128:3303-9.

63. Potzger T, Ried M, Hofmann HS. Decortication in Pleural Empyema: Reasonable Effects on Lung Function. Zentralbl Chir 2016;141 Suppl 1:S18-25.

64. Ravaglia C, Gurioli C, Tomassetti S, et al. Is medical thoracoscopy efficient in the management of multiloculated and organized thoracic empyema? Respiration 2012;84:219-24.

65. Kho P, Karunanantham J, Leung M, et al. Debridement alone without decortication can achieve lung re-expansion in patients with empyema: an observational study. Interact Cardiovasc Thorac Surg 2011;12:724-7. 
66. Chambers A, Routledge T, Dunning J, et al. Is video-assisted thoracoscopic surgical decortication superior to open surgery in the management of adults with primary empyema. Interact Cardiovasc Thorac Surg 2010;11:171-7.

67. Luh SP, Chou MC, Wang LS, et al. Video-assisted thoracoscopic surgery in the treatment of complicated parapneumonic effusions or empyemas: outcome of 234 patients. Chest 2005;127:1427-32.

68. Redden MD, Chin TY, van Driel ML. Surgical versus non-surgical management for pleural empyema. Cochrane Database Syst Rev 2017;3:CD010651.

69. Shirota C, Uchida H. Initial treatment of septated parapneumonic empyema with drainage plus fibrinolytic agents is equally effective as video-assisted thoracoscopic surgery, and is suitable as first-line therapy. Transl Pediatr. 2015;4:41-4.

Cite this article as: Yang W, Zhang B, Zhang ZM. Infectious pleural effusion status and treatment progress. J Thorac Dis 2017;9(11):4690-4699. doi: 10.21037/jtd.2017.10.96
70. Tsoucalas G, Sgantzos M. Hippocrates (ca 460-375 bc), Introducing Thoracotomy Combined With a Tracheal Intubation for the Parapneumonic Pleural Effusions and Empyema. Surg Innov 2016;23:642-3.

71. Arêas CG, Normando Júnior GR, Farias Júnior OS, et al. Parapneumonic pleural effusion: reality and strategies in an Amazon university hospital. Rev Col Bras Cir. 2016;43:424-9.

72. Sziklavari Z, Graml JI, Zeman F, et al. Outcomes of Stage-Adapted Surgical Treatment of Pleural Empyema. Zentralbl Chir 2016;141:335-40.

73. Petrusevska-Marinkovic S, Kondova-Topuzovska I, Milenkovic Z, et al. Laboratory and Radiographic Features of Patients with Pneumonia and ParapneumonicEffusions. Open Access Maced J Med Sci 2016;4:428-34. 